\title{
Acollida i adaptació de les persones amb alts nivell de dependència en centres residencials. Aspectes psicoeducatius per afavorir el procés
}

\section{Cristina Vidal-Martí}

Resum

Una de les decisions més difícils per a una persona dependent i els seus familiars és l'ingrés a un centre residencial. Aquesta decisió comporta una sèrie de canvis tant en la persona com en el seu entorn. Aquest article vol contribuir a visibilitzar la necessitat de tenir cura del procés d'adaptació i facilitar l'acompanyament professional i institucional a fi de poder disminuir l'alt impacte emocional que aquest procés genera. L'article analitza els diferents factors que intervenen en aquest procés $\mathrm{i}$ estableix aspectes psicoeducatius per tal d'afavorir l'acollida i l'ingrés de les persones dependents en el centre residencial.

\section{Paraules clau}

Gent gran, discapacitat, ingrés, acompanyament, suport.

Recepció original: 10 de juliol de 2020

Acceptació: 19 de novembre de 2020

Publicació: 1 de juliol de 2021

Una de les decisions més difícils per a una persona i els familiars de persones dependents és l'ingrés a un centre residencial. Aquesta decisió, que és fruit d'un procés, comporta una multiplicitat de dubtes, neguits, malestar i una sèrie de conseqüències i efectes que incideixen en la salut de la persona que pren la decisió i del seu entorn.

En els darrers anys, la sensibilització per part dels centres residencials i dels seus professionals s'ha incrementat, per tal que aquesta decisió sigui el menys dolorosa possible per la persona i també pel seu entorn. Alguns exemples de mesures instaurades en els centres són l'establiment de protocols organitzatius i de gestió per afavorir que l'adaptació de la persona al centre sigui el més adient i també una major conscienciació per part dels professionals en facilitar l'acompanyament i el suport.

La finalitat d'aquest article és visibilitzar la importància de tenir cura d'aquest procés d'acollida i d'adaptació com un element clau, perquè la persona dependent i el seu entorn s'adapti al centre residencial de la manera més saludable i favorable possible.

\section{L'ingrés. Significat i conseqüències}

Segons IEC, la paraula ingrés significa entrada, accés a una organització, a una residència. Quan una persona ingressa a un centre residencial es pressuposa que hi anirà a viure per un període determinat de temps; la persona viurà en un lloc diferent a casa seva, una organització amb d'altres persones amb situacions similars a les seves, regides per unes normes i on hi treballen uns professionals les 24 hores del dia durant els 365 dies a l'any.

$\left({ }^{*}\right) \quad$ Professora associada del Departament de Mètodes d'Investigació i Diagnòstic en Educació (MIDE) de la Facultat d'Educació de la Universitat de Barcelona. Doctora en psicologia. Educadora social i psicòloga en centres residencials de gent gran. Adreça electrònica: cristinavidal@ub.edu 
L'ingrés és un procés. Un període de canvi en què es produeixen una sèrie de modificacions que suposen una readaptació i una reubicació vital de la persona a la seva nova situació i al seu nou projecte de vida. Com en tot procés de canvi, la vivència està condicionada per múltiples factors i cada situació d'ingrés en un centre residencial és singular, particular i única; com ho són la vivència, les estratègies d'afrontament i d'adaptació de cada persona (Cabodevilla, 2007; Leturia, 1999; Vidal-Martí, 2020). L'organització, a l'igual que la persona, també necessitarà un temps per a conèixer, adaptar-se a la persona i fer possible que participi i arribi a ser un actor i agent actiu de l'organització.

Com en tot procés de canvi, hi ha diferents elements que faciliten l'ingrés de la persona en un centre residencial. Alguns d'aquests elements són: la voluntarietat, la idea preconcebuda de com li agradaria ser cuidada, la participació en el procés de selecció del centre, els recursos personals que disposa la persona, el grau de salut, el suport entre els membres familiars, el procés d'acollida i d'adaptació, els processos organitzatius del centre, entre d'altres (Delgado, 2001; López, Losada, Romero-Moreno, Márquez-González; Martínez-Martín, 2012; Yanguas, 2006; Zamarrón i Fernández-Ballesteros, 2000).

En aquest article, s'exposen cada un d'aquests elements que incideixen en aquest procés, perquè saber-los identificar i conèixer amb més profunditat facilitarà establir mesures, suports i eines preventives i de promoció de la salut.

Leturia (1999) afirma que, durant anys, la literatura científica només s'ha centrat en els efectes negatius que comporta la institucionalització; i és a partir dels anys 90 , que es comencen a visibilitzar els primers estudis en què aquests efectes es positivitzen coincidint amb els canvis de model assistencial i d'atenció a les persones dependents (Ayuso, Pozo i Escribano, 2010; Gaugler, Duval, Anderson i Kane, 2007; IMSERSO, 2006).

\section{El model ACP}

En els últims anys, han conviscut dos enfocaments de l'atenció a les persones amb vulnerabilitat. Aquests són el Centrat en el Servei i el d'Atenció Centrada en la Persona (ACP).

L'enfocament Centrat en el Servei (MCS) s'orienta a la millora del funcionament de l'organització posant l'accent en l'homogeneïtzació del servei d'atenció a les cures i d'intervenció, la millora tecnològica i l'ús d'un llenguatge clínic i tècnic (Abellán i Esparza, 2009).

Per contra, l'enfocament d'Atenció Centrada en la Persona (ACP) es fonamenta en la persona com a nucli de la relació. Busca allunyar-se dels models de cures tradicionals basats en la homogeneïtzació i la unificació de les cures i es centra en el benestar de la persona (Martínez, 2013; 2015). Els principis d'aquest model són: la integritat, la participació, la individualitat, l'autonomia, la intimitat, el benestar, la inclusió social, la continuïtat i la independència (Rodríguez, 2011).

Aquest nou enfocament d'intervenció significa una manera diferent d'entendre, comprendre i atendre a les persones amb vulnerabilitat. L'objectiu és «aconseguir la miIlora de la qualitat de vida en tots els àmbits de la persona, partint del respecte a la seva dignitat, als seus interessos, drets, preferències i tenint en compte la seva participació activa en tot el procés» (Rodríguez, 2011, p. 106).

L'Atenció Centrada en la Persona (ACP) neix en els països nòrdics i s'implementa a la resta de països de manera progressiva amb la voluntat de canviar el paradigma d'atenció i d'intervenció a les persones dependents amb vulnerabilitat. Aquest nou model busca 
que la persona sigui un agent actiu i tingui un rol dinàmic, promocionant l'apoderament de la persona.

La tasca dels professionals s'orienta a facilitar l'acompanyament, en la mesura que ho necessiti, en la presa de decisions que afecten la seva vida (Martínez, Díaz-Veiga, Sancho i Rodríguez, 2014). Es tracta d'impulsar i promoure l'apoderament de la persona a través de l'acompanyament i l'escolta activa, amb la finalitat d'ajudar la persona dependent a desenvolupar cada una de les seves capacitats (Martínez et al., 2014).

L'enfocament subratlla la importància que el professional reforci les capacitats i potencialitats de la persona, entenent l'atenció professional com un fet facilitador de suports, en què la història de vida de la persona es tingui en consideració. En definitiva, el model d'Atenció Centrada en la Persona promou que la persona segueixi tenint el control de la seva vida, la capacitat de satisfer els seus desitjos, anhels, capacitats i la seva voluntat amb la finalitat que sigui ella mateixa qui planifiqui i realitzi els seus objectius i projectes vitals.

\section{Mites que condicionen l'elecció del centre o l'ingrés}

El desconeixement, la manca d'informació i les generalitzacions faciliten que el nombre de mites i creences errònies augmentin en el moment de l'ingrés i en el procés d'acollida en un centre residencial. Amb la finalitat de trencar aquests prejudicis, el primer pas serà identificar-los, donar informació i treballar per a minimitzar-los.

Al nostre entendre, hi ha sis mites que necessiten ser visibilitats per trencar unes idees que no es sustenten en el coneixement científic, sinó en excepcions o generalitzacions fruit del desconeixement dels recursos.

Un primer mite és ser cuidat a casa. Aquest mite, que persisteix en la nostra societat, estableix que la persona dependent està més ben atesa a casa que en un centre residencial. Aquesta creença es justifica en base a la voluntat de com la persona vol ser cuidada i en la vulneració social dels seus drets com a individu (Goffman, 2001; Human Rights Watch, 2010; Pie, 2012; Huete, Huete i Martín, 2015). Tanmateix, el nombre d'atencions que demanda una persona amb alts nivells de dependència justifiquen la importància de la institucionalització (IMSERSO, 2006).

Si la persona al llarg de la seva vida, ja sigui per desconeixement dels serveis d'atenció o per tradició familiar, es diu a si mateixa que serà cuidada per familiars propers, amb una alta probabilitat, aquesta persona presentarà més resistències respecte aquelles que volen trencar aquesta situació i demanen ajuda externa per ser cuidades (Pinzón-Pulido et al., 2016).

Un segon mite és que en un centre residencial petit hi ha una millor atenció. Aquest mite reflecteix una preferència de la persona. No s'han trobat estudis en què s'evidenciï que la mida del centre residencial està relacionat amb la sensació de benestar. Tanmateix, sí que hi ha estudis sobre la qualitat de vida en els centres residencials i investigacions d'implementació de sistemes de qualitat però, en cap cas, analitzen la variable mida del centre com un valor (Sanz, Santiago i Cámara, 2011).

La titularitat del centre és un tercer mite. En la nostra societat es considera que en un centre residencial de caràcter públic garanteix una millor atenció assistencial respecte el 
privat. A l'igual que succeeix amb el segon mite, a dia d'avui no s'han trobat dades objectivables en què les investigacions relacionin el benestar subjectiu i la qualitat de vida en relació a la titularitat.

De tota manera, convé recordar que més d'un 70\% dels centres residencials a l'estat espanyol són de titularitat privada i un alt percentatge d'aquests disposen de mecanismes de concertació i/o col-laboració amb l'administració (Esteban i Rodríguez, 2015). Això significa que hi ha un finançament públic en els centres de titularitat privada i la diferència entre la titularitat del centre per la persona o la família queda desdibuixada, ja que un $72 \%$ de les places residencials son concertades (Esteban i Rodríguez, 2015).

Un quart mite és la mala relació entre la persona que ingressa al centre residencial i la família (López, Noriega, Velasco i Moya-Faz, 2015). Aquesta creença no es generalitzable i, per tant, dependrà de cada cas. Diferents estudis estableixen que els motius pels quals les persones ingressen en un centre residencial són per l'increment de la dependència física i/o mental i/o la manca de xarxa familiar (Freedman, 1996; Grundy i Jitlal, 2007; Zueras i Ajenjo, 2016). Tot i el canvi de mentalitat i creences, hi ha persones que opten per ingressar a un centre residencial perquè «no volen ser una càrrega» pels seus familiars o per motius més pragmàtics (comoditat, atenció, ...) (Zueras i Ajenjo, 2016).

L'índex de rebuig és un cinquè mite. A dia d'avui no s'ha trobat estudis que expliquin quin percentatge de persones dependents, que ingressen en un centre residencial, l'abandonen com tampoc quin és el possible motiu pel qual ho fan. Aquesta dada seria $d^{\prime}$ 'interès conèixer, perquè es tendeix a pensar que les persones que ingressen en el centre ho fan per viure la resta de la seva vida, però aquesta creença es desconeix si és certa i conseqüentment el seu desconeixement retroalimenta aquest mite.

El darrer mite és el tracte rebut en els centres residencials per part dels professionals d'atenció directa. El desconeixement comporta que famílies i persones reforcin la idea preconcebuda que l'atenció en un centre residencial no és adequat i que una atenció per part d'un cuidador informal, un familiar, és una millor opció. En els transfons d'aquest mite hi ha la creença que el professional pot tractar de manera inadequada o exercir un mal tracte vers la persona dependentment.

Aquest mite que persisteix en la nostra societat ha estat invalidat pels estudis de cura (Knowles et al., 2016; Pearlin et al., 1990). Posposar la institucionalització comporta un major risc de sobrecàrrega objectiva i subjectiva del cuidador principal i conseqüentment incrementa la probabilitat que la família sigui l'agent maltractador (Alonso, Velázquez i Ramón, 2010; Bazo, 2006; Gil i Navas, 2017; Nolan, 2000).

En l'actualitat, es disposen d'instruments que permeten identificar la càrrega de la cura i avaluar-ne les seves conseqüències. Aquests són l' Índex de l'esforç del cuidador (Vitaliano et al., 1991) i l'escala de Sobrecarrega del Cuidador (Zarit, Reever i Bach-Peterson, 1980). Aquestes eines s'han convertit en instruments predictors de la institucionalització (Babarro et al., 2004).

En definitiva, si la persona i/o el seu entorn tenen aquests mites o d'altres relacionats amb l'ingrés a un centre residencial, l'objectiu és fer-los conscients com a primer pas per revisar aquestes creences limitadores, que poden dificultar el seu procés d'adaptació. 


\section{Fases en el procés d'acollida i d'adaptació al centre}

Es diferencien tres fases en el procés d'acollida i d'adaptació al centre residencial (Leturia, 1999). Una primera anomenada pre-ingrés, que tal com el seu nom indica, és una fase prèvia a l'ingrés de la persona i de la família en el centre. És una etapa d'alta intensitat emocional que es caracteritza, perquè és quan es pren la decisió i es realitzen les primeres accions per iniciar la institucionalització. Una segona, anomenada ingrés, que es produeix quan la persona entra i ingressa en el centre residencial; i una tercera, denominada postingrés, que correspon al període posterior a l'ingrés i en què la persona inicia el seu procés d'adaptació. A continuació, s'analitza cada una d'aquestes fases amb detall.

\section{Fase de pre-ingrés}

Aquesta fase es divideix en dos moments diferenciats. Un moment caracteritzat per una alta càrrega emocional com és la presa de decisions i un segon marcat per l'elecció i la tria del centre residencial.

La presa de decisions és una situació estressora, condicionada per diferents situacions i elements que tenen una major o menor incidència. Tal com s'apuntava en l'apartat anterior, qui pren la decisió, el motiu, la creença de com vol ser la persona cuidada, l'estat de salut, el temps dedicat a la decisió, els mites cap als centres residencials, els aspectes organitzatius... condicionen la decisió de manera notable.

Si la persona pren la decisió d'ingressar en un centre residencial, a priori, el procés d'acollida i d'ingrés per la pròpia persona i l'entorn familiar serà més senzill. Per contra, la situació pot agreujar-se en els casos en què la persona no ha escollit aquest ingrés de manera voluntària ni tampoc no se li ha explicat de manera clara ni comprensible (López et al., 2012; Pinzón-Pulido el al., 2016).

En la nostra societat, l'ingrés residencial per part de les persones dependents és relativament recent i, en termes generals, poc acceptat (Zueras i Ajenjo, 2016). L'augment de l'esperança de vida i els canvis estructurals que han incidit en el si familiar han contribuït a què les persones grans dependents i les persones amb discapacitat no puguin ser cuidades per la família (Gómez, Fabra i Vila, 2018). Els familiars propers davant la incapacitat de poder tenir cura dels seus progenitors o familiars propers busquen un centre residencial que atengui a la persona de manera més integral, holística, situant-la al centre de l'atenció i en base a uns principis humanitzadors. Aquesta decisió, que no forma part d'un imaginari col-lectiu de les persones grans actuals, genera una sèrie de resistències i creences errònies condicionades per qüestions de caràcter cultural i per desconeixement dels centres residencials.

Al nostre entendre, la projecció de com la persona vol ser cuidada incideix de manera directa en la conducta i en la gestió emocional de l'adaptació de la persona. És a dir, si la persona al llarg de la seva vida és reitera que vol mantenir l'ideal de ser cuidada pels seus familiars o bé continuar la tradició cultural de la cura familiar, quan la persona ingressi en un centre viurà una situació de xoc que haurà de gestionar per tal d'adaptar-se de manera òptima. En definitiva, es tracta d'un procés de dol i, com a tal, si la situació és esperada la gestió i l'afrontament és més realista i més saludable respecte a l'inesperat i al no previst.

Un tercer aspecte que condiciona el procés d'acollida és l'estat de salut (Pac, Mascaró i Riveiro, 2006). Un bon estat de salut possibilita a la persona a ampliar els propis recursos; 
per contra, un deteriorament de l'estat de salut, ja sigui de tipus cognitiu, funcional o físic afecta les estratègies d'afrontament (Barreto, Yi i Soler, 2008). En definitiva, els problemes de salut mental, emocional o de dolor crònic són elements obstaculitzadors del procés d'acollida, adaptació i acceptació de la persona a la seva situació (López et al., 2012; Luppa et al., 2010).

El temps dedicat a la decisió pot condicionar de manera notable. Si la decisió és voluntària, la presa de decisió de l'ingrés és un procés que pot fluctuar en el temps mentre la persona i/o la seva família valora si continua vivint en el domicili amb suports o en un centre residencial. Tanmateix, quan la decisió no està consensuada o no està presa el nivell de tensió familiar augmenta i condiciona el temps per prendre la decisió.

I un darrer punt a tenir en consideració són els aspectes organitzatius del centre residencial i com es concreten en els seus protocols i en les actuacions que els professionals realitzen. Un centre residencial que vetlli per una càlida atenció, orientada a la persona i amb uns protocols d'acollida coherents, realistes i que parteixin de les necessitats de les persones ateses facilitaran l'adaptació de la persona en el centre residencial.

En el moment de la tria del centre és important que la persona -en la mesura que pugui- i la seva família visitin els diferents centres escollits i valorin la idoneïtat. Aquestes visites tenen una doble finalitat; per una banda, conèixer la residència i, per l'altra, informar-se de tota la documentació que es necessitarà per formalitzar l'ingrés i la seva gestió.

La persona i la família pot optar a fer una segona visita en el moment de l'elecció del centre. Tanmateix, independentment del nombre de visites, en aquest moment des del centre es tendeix a recopilar informació com: preguntar els motius de l'ingrés, conèixer la família (la composició familiar, la distribució dels rols familiars...) i les expectatives familiars i explicar i informar del funcionament del centre (normes de funcionament, reglament de règim intern, festes...). És un bon moment per donar per escrit la documentació per a formalitzar l'ingrés; és a dir, especificar tota la informació (documentació, roba, estris de cura personal...) que la persona necessita per ingressar al centre residencial, respondre a les preguntes o dubtes que té la persona i la família i concretar el dia i l'hora d'ingrés.

En definitiva, aquesta fase de pre-ingrés és un moment d'alta intensitat emocional i en funció de la personalitat, les estratègies d'afrontament, la tria de la decisió, la voluntarietat i l'estat de salut condicionen el procés. Per tant, la tasca d'acompanyament tant a nivell organitzacional com a nivell més professional serà crucial per donar suport i facilitar la canalització emocional de la situació.

\section{Fase de l'ingrés}

El més característic de la fase de l'ingrés és l'establiment del dia i l'hora en què la persona ingressarà al centre residencial. És un moment delicat i emotiu. En aquesta fase, trobem que hi ha centres que estableixen dos moments diferenciats. Un primer, més de caràcter administratiu i de gestió, orientat a complimentar la documentació per a fer l'ingrés; i un segon, de caràcter més humà, orientat a l'acollida i fer que l'ingrés sigui més fàcil i còmode per la persona i la família. 
En alguns centres residencials, es minimitza el moment de la gestió per intensificar més l'acompanyament de la persona i de la família en l'ingrés. Al nostre entendre, reforçar el suport, la cooperació i l'acompanyament de la persona i de la família és cabdal per facilitar l'elaboració del dol i facilitar la gestió emocional.

És convenient recordar que aquesta fase és un moment estressor i colpidor a nivell emocional. Un bon saber estar i un acompanyament facilitarà que la situació es gestioni d'una manera més saludable i òptima. En aquest moment, el sentiment de culpa pot estar present $\mathrm{i}$ el desplegament de competències professionals per a guiar i acompanyar la família són bàsics per a facilitar l'ingrés de la persona dependent.

En aquesta fase, una de les tasques dels professionals és acompanyar la persona i la família físicament pel centre amb l'objectiu de situar-se, dirigir-la a la seva estança i clarificar els dubtes que la persona o la seva família tinguin. En el moment pròpiament que la persona ingressa, la persona o la família poden presentar indecisió, dubtes, sentiments de culpa... I'ajuda i l'acompanyament és cabdal perquè la persona i el seu entorn se senti acollida i conseqüentment actituds empàtiques, de suport i d'escolta activa poden facilitar la gestió d'aquest moment d'un alt impacte emocional.

\section{Fase del post-ingrés}

La fase del post-ingrés és la darrera fase del procés d'acollida. En aquesta fase, és important seguir acompanyant la persona amb un alt nivell de dependència així com també la seva família. Per tant, donar resposta a les possibles preguntes que plantegen les famílies i la persona gran i realitzar les tasques de suport que requereixin la persona o la família amb la finalitat d'afavorir el procés d'integració de manera progressiva.

En aquesta fase, les funcions dels professionals son dues. Una és afavorir la implicació i la participació de la persona en el centre residencial, tant en les activitats de suport que la persona necessita en les seves Activitats de la Vida Diària (AVD) com en la resta d'àrees: lleure, espais lúdics no organitzats, .... Quan més participa la persona més s'incentiva la motivació i es promou la implicació d'una manera més saludable i òptima (Barenys, 2012).

Una segona és facilitar a les persones $i$ a les seves famílies conèixer la dinàmica del centre. Donar i recordar informacions, fer preguntes per saber si tenen algun dubte, diversificar els canals de comunicació perquè arribi la informació del funcionament del centre... seran algunes actuacions que faciliten a la persona i a la seva família situar-se i adaptar-se a la dinàmica institucional.

Un indicador que pot ajudar a predir el grau d'adaptació i acollida de la persona dependent i la família en el centre són les enquestes de satisfacció. Aquests criteris de qualitat permeten tenir una informació precisa i global del grau de benestar de la persona i del seu entorn. Els seus resultats són tendències, que ben analitzades, proporcionen informació tant objectiva com subjectiva de la valoració dels diferents serveis del centre residencial, permeten identificar i valorar el grau d'assoliment de les necessitats i demandes de les persones i dels seus familiars així com també saber aquella informació relacionada amb les expectatives de les persones i la seva gestió.

Un segon indicador per valorar el procés d'adaptació és el grau de conformitat amb el procés d'institucionalització. Això significa el nivell en què la persona modifica el seu comportament, actitud o opinió per tal d'adaptar-se i integrar-se en el centre residencial. 
Si una persona adopta actituds dúctils i flexibles tindrà més probabilitat d'adaptar-se a la institució perquè és capaç de modificar perspectives, actituds i pensaments.

\section{Acompanyament a la família}

Al llarg del tot el procés d'ingrés, la família viu uns sentiments ambivalents d'una alta intensitat emocional. L'acompanyament i el suport personalitzat per part dels professionals així com també una comunicació fluida, àgil i càlida seran importants per a facilitar el procés d'ingrés de la persona i la seva família en el centre residencial.

La família és un dels pilars fonamentals de la persona dependent. La cura d'aquesta unitat significa, en part, la cura de la persona que ingressa al centre residencial. És a dir, la família és un peça clau i referent per a la persona amb dependència (López et al., 2015). Independentment del tipus de vincle, la relació entre la persona dependent i la família es basa en aliances com a font de benestar i de seguretat (Araújo, Jesús, Araújo i Ribeiro, 2017; Marrugat, 2005).

Tanmateix, hi ha factors previs al procés de l'ingrés que condicionen tant en les dinàmiques i les relacions familiars com també en la decisió i en el procés d'ingrés d'una persona en un centre. Aquests factors previs són: el tipus de vincle entre la persona dependent i la seva família, els mites propis de la família en relació a la cura i els mites que la família té dels centres residencials.

Si la família i la persona dependent tenen una relació d'alta dependència emocional o una situació de claudicació familiar a causa del procés d'emmalaltir-se o del desgast de l'atenció i la cura de la situació de dependència, el grau d'acompanyament haurà d'identificar-se, amb la finalitat que la persona i el seu entorn trobin els recursos i els espais per adaptar-se i acomodar-se a la nova situació (Araújo et al., 2017).

L'acompanyament a la família s'haurà de fer en el procés d'acollida, tant en el postingrés com al llarg del període en què la persona convisqui i visqui en el centre residencial. El grau i la intensitat variaran en el temps i l'acompanyament passarà a ser d'una tècnica a una filosofia d'intervenció.

\section{Protocol d'acollida: una eina organitzativa per afavorir l'adaptació}

Un protocol és un instrument a nivell organitzatiu amb la finalitat de facilitar el bon funcionament de la institució i establir unes pautes unitàries i consensuades d'actuació dels professionals. Aquesta eina contribueix a una millora de l'atenció integral de les persones i facilita la participació dels professionals en aspectes organitzacionals, d'intervenció i de coordinació.

Els principals beneficis dels protocols són tres. Un primer és facilitar la comunicació interna entre els professionals del centre; un segon, és establir una mateixa manera de procedir, això significa que hi ha d'haver un treball de coordinació entre els diferents professionals per tal que disposin d'una mateixa informació que els permetrà saber què fer i com actuar; i un tercer benefici és promocionar el clima i la fluïdesa comunicativa entre els agents implicats i que intervenen en la persona.

L'eficàcia d'un protocol radica en el treball previ d'elaboració i la revisió de la seva implementació. La implicació de tots els professionals, el consens, i establir uns procediments ordenats, coherents i realistes a les necessitats del centre facilitaran la confecció 
d'aquest document, però serà necessària la vivesa del document; és a dir, que els procediments per part dels professionals siguin interioritzats i aplicats i, en cas de no ser adequats, canviar-los.

El protocol és una eina dinàmica. Això significa que davant de qualsevol canvi el document necessitarà ser modificat i s'haurà d'adaptar a les noves necessitats. Tot protocol facilita l'organització dels professionals al centre. En relació a l'acollida, el protocol té més sentit perquè al ser un procés en el qual hi ha moments estressors i d'alta intensitat emocional, facilita que els professionals prenguin consciència del fet i estableixin les mesures comunicatives i d'acompanyament precises.

La Generalitat de Catalunya, arran d'un canvi legislatiu en què es demanava als centres residencials disposar d'aquesta eina, proposà un esquema. (Departament de Treball, Afers Socials i Famílies, 2019)

\section{Esquema de Protocol d'acollida i adaptació}

\begin{tabular}{|c|c|}
\hline Definició: & PROTOCOL D'ACOLLIDA I ADAPTACIÓ \\
\hline Objectiu: & Facilitar l'adaptació del nou resident al centre. \\
\hline $\begin{array}{l}\text { Població a } \\
\text { qui va diri- } \\
\text { git: }\end{array}$ & A tot nou resident. \\
\hline $\begin{array}{l}\text { Professio- } \\
\text { nals impli- } \\
\text { cats: }\end{array}$ & Tot el personal del centre vetllarà per l'aplicació del protocol. \\
\hline $\begin{array}{l}\text { Descripció } \\
\text { de l'actua- } \\
\text { ció: }\end{array}$ & $\begin{array}{l}\text { Descriure per ordre els passos a seguir: } \\
\text { 1. Fer un recorregut per la residència amb el nou resident perquè conegui el cen- } \\
\text { tre i la seva habitació. } \\
\text { 2. Formalitzar la documentació d'ingrés (contracte, informe mèdic previ a l'in- } \\
\text { grés,...). } \\
\text { 3. Explicar els mecanismes d'informació als residents i, si s'escau, de la participa- } \\
\text { ció, així com els costums de la residència. } \\
\text { 4. Ajudar el resident a instal-lar-se a l'habitació amb les seves coses. } \\
\text { 5. Presentar-li el personal del centre i els companys (en general i els de referèn- } \\
\text { cia). } \\
\text { 6. Facilitar l'adaptació del resident a la nova situació personal. } \\
\text { 7. Seguiment i valoració del procés d'adaptació (durant } 3 \text { mesos). }\end{array}$ \\
\hline $\begin{array}{l}\text { Elaboració i } \\
\text { vigència: }\end{array}$ & $\begin{array}{l}\text { Es farà constar la data de realització, professionals que l'han elaborat, vigència } \\
\text { del protocol, data prevista de valoració del funcionament i signatura dels que } \\
\text { l'han elaborat. }\end{array}$ \\
\hline $\begin{array}{l}\text { Data de revi- } \\
\text { sió i signa- } \\
\text { tura: }\end{array}$ & $\begin{array}{l}\text { La revisió es durà a terme en la data prevista o abans si es creu convenient. Cal- } \\
\text { drà que hi consti quins professionals I'han revisat tant si hi ha modificacions com } \\
\text { si no n'hi ha (si és possible els mateixos que l'han elaborat), data i signatura. }\end{array}$ \\
\hline
\end{tabular}

A mode d'il.lustració, seguidament, es presenta un exemple real d'un protocol d'un centre residencial de gent gran.

\section{Protocol d'acollida i d'adaptació}

\section{Objectius}

- Facilitar l'acollida i l'ingrés dels nous residents.

- Promoure l'adaptació de la persona resident i de la família a la residència.

Població a la qual s'adreça

Aquest protocol va dirigit a totes les persones grans que ingressin a la residència com a nous residents. 


\section{Professionals implicats}

En aquest protocol, els professionals implicats són: I'equip directiu, la responsable higiènic-sanitària, la infermera, el treballador social, la psicòloga, l'educador social i l'equip d'auxiliars de geriatria.

\section{Descripció de l'actuació}

La residència disposa d'un equip de professionals capacitats per a portar a terme aquest protocol; implicant-se de manera activa el treballador social, la directora, la infermera, l'equip d'auxiliars i la psicòloga.

L'actuació en el protocol d'acollida es divideix en tres moments:

Pre-ingrés

El pre-ingrés consisteix en una entrevista que la persona interessada i/o el seu familiar manté amb la directora de la residència.

Els punts que s'aborden en aquesta primera trobada són:

- La directora de la residència mostra les instal.lacions.

- La directora explica el funcionament intern de la residència, els serveis que disposa, els professionals que treballen i les tarifes.

- Si la persona interessada manifesta voler ser resident es prosseguirà a:

- La directora sol-licita les dades d'identificació de la persona i la família.

- Firmar el contracte de la prestació de serveis assistencials per triplicat: una còpia serà per la persona resident, una altra còpia pel familiar responsable i l'última per a la residència.

- La directora lliura el document de reglament de règim interior de la residència a la persona gran.

Una vegada s'ha formalitzat el contracte de la prestació assistencial i realitzat les gestions administratives, la directora lliurarà a la persona un llistat en què es detalla la relació d'objectes, roba personal i documentació que haurà de portar el dia de l'ingrés.

Ingrés

En el moment de l'ingrés, la directora o el professional delegat (en cas que la directora no estigués a la residència) acollirà a la nova persona resident i la presentarà als residents i als professionals. Seguidament, l'auxiliar de referència l'acompanyarà a la seva nova habitació, l'ajudarà a instal-lar-se i respondrà a tots aquells dubtes que la persona tingui.

Els professionals facilitaran l'adaptació del resident a la nova situació personal.

\section{Post-ingrés}

Els professionals realitzaran una valoració del procés d'adaptació i de seguiment del nou resident durant els primers sis mesos per indicar el grau d'adaptació a la nova situació. Al llarg d'aquest període es faran entrevistes amb la persona o la família per conèixer la seva història de vida i elaborar conjuntament amb la persona el Pla d'Aten- 
ció $i$ Vida. La psicòloga farà trobades informals amb la persona al llarg d'aquests mesos per anar valorant el seu procés d'adaptació de manera informal i el treballador social farà el mateix amb la família.

Elaboració, valoració, vigència i data de revisió

Aquest protocol ha estat elaborat pel XXXX (nom i cognoms dels professionals) en la data (especificar dia, mes i any).

La data prevista de la valoració del seu funcionament és el XXX (especificar dia, mes i any).

La data prevista de revisió serà el XXX (especificar dia, mes i any).

\section{Altres aspectes psicoeducatius per afavorir l'ingrés}

Al llarg de l'article, s'incideix en la importància de tenir cura al llarg del procés d'acollida. En aquest últim apartat, a mode de resum, es detallen sis aspectes psicoeducatius per tal d'afavorir la implementació d'aquestes mesures.

Un primer aspecte és implicar a la persona i el seu entorn, en tot moment, amb la finalitat que siguin el centre de l'atenció i es vetlli per un acompanyament al llarg de tot el seu procés d'ingrés. És a dir, facilitar que siguin agents actius i participatius en el procés.

El suport i el fet d'estar al costat de la persona i el seu entorn afavorirà el sentiment d'escolta, d'ajuda i suport com instruments de facilitació de l'acollida i l'ingrés. Si els professionals tenen present la singularitat, els gustos i els interessos de la persona això beneficiarà el procés.

La sensibilització institucional és el segon aspecte. Les persones amb alts nivells de dependència són col-lectius d'una d'alta vulnerabilitat i fragilitat. Per aquest motiu, establir mesures d'adaptació i d'acompanyament serà crucial per conscienciar els professionals i tots els agents implicats de la necessitat de vetllar perquè l'atenció, la cura i l'acompanyament garanteixin el respecte i les mesures necessàries per afavorir l'ingrés de la persona i els seus familiars.

Un tercer aspecte és respondre els dubtes, inquietuds i demandes que té tant la persona que ingressa a un centre residencial com la seva família. Donar resposta a les necessitats que planteja la persona és una tasca d'orientació i de guiatge, que facilitarà una disminució del nivell d'ansietat de la persona i de l'entorn (Leturia, Inza i Hernández, 2011).

Al llarg del procés d'adaptació, la persona que ingressa i el seu entorn viuen un període d'alta intensitat emocional. El desenvolupament i la millora de les competències comunicacionals i relacionals per aproximar-se, com a professionals, a la vulnerabilitat i el malestar són primordials en el procés d'acompanyament.

Les actituds dels professionals són eines moduladores que poden afavorir el procés de manera saludable; o per contra dificultar-ne l'adaptació. Això significa que un procés educatiu dels professionals permet la revisió de les pròpies actituds i es converteix en una eina cabdal a tenir en compte en el si de l'organització. 
Si es considera que educar és intervenir, guiar, acompanyar a la persona i possibilitar el seu procés evolutiu de manera regulada i sistèmica, la comunicació és una de les estratègies i habilitats a reaprendre i reavaluar (Comella, 2009). Saber crear espais i recursos de comunicació fluids, facilitadors de canvi que possibiliten visibilitzar perspectives, canvis de narrativa i de percepcions per tal d'afrontar la situació estressora de l'acollida i l'ingrés de la manera més saludable possible.

El sisè aspecte és la promoció de la comunicació i l'organització en si del centre residencial. L'establiment d'un clima afavoridor de la comunicació, una comunicació estratègica en què s'estableixin tant els aspectes organitzacionals com també aquells elements que promoguin l'excel·lència d'atenció i d'intervenció a la persona.

Això significa una planificació acurada i real de les possibles necessitats de les persones a fi de poder detectar-les quan es produeixin i establir les mesures comunicacionals d'acompanyament i relacionals necessàries (Vidal-Martí, 2016).

En resum, el procés de l'ingrés d'acollida i d'adaptació d'una persona amb alts nivells de dependència en un centre residencial ha de ser integral, individualitzat, afavoridor de la inclusió i en què es tingui present la persona des de les diferents dimensions (física, emocional relacional, cognitiva i espiritual). Tot i l'esforç realitzat en els últims anys per part dels centres residencials, l'autora d'aquest article no ha sabut trobar recerques ni estudis que identifiquin i analitzin amb detall quins són els factors afavoridors del procés d'acollida i d'adaptació.

Tot i que en l'actualitat, hi ha una tendència ideològica i pedagògica a la desinstitucionalització pels efectes que genera (Goffman, 2001; Human Rights Watch, 2010; IMSERSO, 2006; Pie, 2012), els centres residencials donen respostes integrals a les necessitats de les persones amb alta dependència. Per tant, tenint en compte aquesta necessitat, aquest article vol contribuir a visibilitzar la importància de tenir cura del procés d'adaptació i d'acollida d'una persona amb alt nivell de dependència en un centre residencial per a facilitar-ne l'acompanyament.

\section{Referències}

Abellán García, A. i Esparza Catalán, C. (2009) Solidaridad familiar y dependencia entre las personas mayores. Informes Portal Mayores, 99. Madrid, Portal Mayores.

Alonso, M.D.C.F.; Velázquez, S. H., i Ramón, S. S. (2010) «Atención a situaciones de violencia en atención primaria: parte II: personas mayores e infancia». FMC: Formación Médica Continuada en Atención Primaria, 17(1), p. 7-21.

Araújo, I.; Jesús, R.; Araújo, N. i Ribeiro, O. (2017) «Percepción del apoyo familiar del adulto mayor institucionalizado con dependencia funcional». Enfermería universitaria, 14(2), p. 97-103.

Ayuso Gutiérrez, M.; Pozo Rubio, R. D. i Escribano Sotos, F. (2010) «Factores sociodemográficos y de salud asociados a la institucionalización de personas dependientes». Revista Española de Salud Pública, 84(6), p. 789-798.

Barenys, M. P. (2012) «Los geriátricos, de la institucionalización al extrañamiento». Revista Kairós: Gerontología, 15(4), p. 7-24.

Babarro, A. A., Barral, A. G., Ponce, A. D., Ruiz, R. C., i Pastor, M. R. (2004) «Perfil y sobrecarga de los cuidadores de pacientes con demencia incluidos en el programa ALOIS». Atención primaria, 33(2), p. 61-67. 
Barreto, P.; Yi, P. i Soler, C. (2008) «Predictores de duelo complicado». Psicooncología, 5, p. 383-400.

Bazo, M. T. (2006) «Incidencia y prevalencia del maltrato de los mayores» a El maltrato de personas mayores: detección y prevención desde un prisma criminológico interdisciplinar. País Vasco: Hurkoa Fundazoia y el Instituto Vasco de Criminología, p. 3961.

Cabodevilla, I. (2007) «Las pérdidas y sus duelos». Anales del Sistema Sanitario de Navarra, 30 (Supl. 3), p. 163-176.

Comella Carbó, M. J. (2009) Educar en la comunidad y en la familia: acompañando a las familias en el día a día. Valencia, Nau Llibres.

Delgado, M. L. (2001) «Intervención psicosocial en residencias para personas mayores». Cuadernos de trabajo social, 14, p. 323-340.

Departament de Treball, Afers Socials i Famílies (2019) Organització interna. Generalitat de Catalunya. Recuperat de

https://treballiaferssocials.gencat.cat/ca/ambits_tematics/serveis_socials/entitats_s erveis_i_equipaments_socials/condicions_de_funcionament_dels_establiments_re sidencials/organitzacio_interna/ [Accés: 28.8.2020]

Esteban Herrera, L. i Rodríguez Gómez, J. Á. (2015) «Situaciones de dependencia en personas mayores en las residencias de ancianos en España». Ene, 9(2). Recuperat de http://ene-enfermeria.org/ojs/index.php/ENE/article/view/546/ancianos [Accés: 4.10.2020]

Freedman, V. A. (1996) «Family structure and the risk of nursing home admission». Journal of Gerontology: Social Sciences, 51(2), p. S61-S69.

Gaugler, J. E.; Duval, S.; Anderson, K. A. i Kane, R. L. (2007) «Predicting nursing home admission in the US: a meta-analysis». BMC geriatrics, 7(1), p. 13.

Gil, J. S. i Navas, M. F. (2017) «Consecuencias del burnout de cuidadores de pacientes con demencia». European Journal of Health Research (EJHR) 3(2), p. 119-126.

Goffman, E. (2001) Internados. Buenos Aires, Amorrortu.

Gómez i Serra, M.; Fabra Fres, N. i Vila Mumbrú, C. (2018) «Pedagogia social, vellesa i autonomia personal». Temps d'Educació, 54, p. 239-254.

Grundy, E. i Jitlal, M. (2007) «Socio-demographic variations in moves to institutional care 1991-2001: a record linkage study from England and Wales». Age and ageing, 36 (4), p. 424-430.

Huete, A.; Huete, M.A. i Martín, A. (2015) Institucionalización de las personas con discapacidad en España. Madrid, Observatorio Estatal de la discapacidad.

Human Rights Watch (2010) Once you enter, you never leave. Deinstitutionalizacion of persons with intelectual or mental disabilities in Croatia. New York, Human RightsWatch.

Instituto de Mayores y Servicios Sociales (IMSERSO) (2006) Institucionalización y Dependencia. Madrid, IMSERSO.

Knowles, S.; Combs, R.; Kirk, S.; Griffiths, M.; Patel, N., I Sanders, C. (2016) «Hidden caring, hidden carers? Exploring the experience of carers for people with long-term conditions». Health \& Social Care in the Community, 24(2), p. 203-213.

Leturia, F. J.; Inza, B. i Hernández, C. (2011) «El papel de la familia en el proceso de atención a personas mayores en centros sociosanitarios». Matia-Zerbitzuan, 41, p. 129-144. 
Leturia Arrazola, F.J. (1999) «El proceso de adaptación en centros residenciales para personas mayores». Revista Española de Geriatría y Gerontología, 34 (2), p. 59-122.

López, J.; Losada, A.; Romero-Moreno, R.; Márquez-González, M. i Martínez-Martín, P. (2012) «Factores asociados a la consideración de ingresar a un familiar con demencia en una residencia». Neurología, 27 (2), p. 83-89.

López, J.; Noriega, C.; Velasco, C. i Moya-Faz, F. J. (2015) «Conflictos familiares cuando se cuida a un familiar mayor». Familia, 51, p. 17-29.

Luppa, M.; Luck, T.; Weyerer, S.; König, H. H.; Brähler, E. i Riedel-Heller, S. G. (2010) «Prediction of institutionalization in the elderly. A systematic review». Age and ageing, 39 (1), p. 31-38.

Martín Pindado, L. (2012) «La opinión y los deseos de las personas mayores» a Innovaciones en residencias para personas mayores en situación de dependencia. Madrid, Fundación Caser para la dependencia, p. 229-234.

Martínez Rodríguez, T. (2013) La atención centrada en la persona. Algunas claves para avanzar en los servicios gerontológicos. Madrid, Fundación Caser para la dependencia.

Martínez Rodríguez, T. (2015) La atención centrada en la persona en los servicios gerontológicos: modelos de atención e instrumentos de evaluación. Tesis doctoral. Oviedo, Facultad de Psicología.

Martínez, T.; Díaz-Veiga, P.; Sancho, M. i Rodríguez, P. (2014) Modelo de atención centrada en la persona. ¿En qué consiste este modelo de atención? Recuperat de https://www.euskadi.eus/contenidos/informacion/publicaciones_ss/es_publica/adj untos/cuaderno\%201.pdf [Accés: 12.7.2020]

Marrugat, M. L. (2005) «La familia cuidadora y su incidencia en la calidad de vida de las personas dependientes». Revista multidisciplinar de gerontología, 15 (3), p. 171-177.

Nolan, M. (2000) «Las relaciones cuidador-persona dependiente y la prevención del maltrato a los ancianos" a El maltrato a las personas mayores. Barcelona, Paidós, p. 1756.

Pac, P.; Mascaró, J. i Riveiro, P.V. (2006) «Motivos de ingreso en residencias geriátricas en Calahorra (La Rioja)». Revista multidisciplinar de gerontología, 16 (1), p. 32-36.

Pearlin, L. I.; Mullan, J. T.; Semple, S. J.; i Skaff, M. M. (1990) «Caregiving and the stress process: An overview of concepts and their measures». The gerontologist, 30(5), p. 583-594.

Pié, A. (Coord.) (2012) Deconstruyendo la dependencia: propuestas para una vida independiente. Barcelona, UOC.

Pinzón-Pulido, S.; Pena, F. G.; Alcázar, V. R.; Lima-Rodríguez, J. S.; Triano, M. F. R.; Domene, M. M. i Trujillo, F. A. (2016) «Factores predictores de la institucionalización de personas mayores en situación de dependencia en Andalucía». Enfermería clínica, 26 (1), p. 2330.

Rodríguez, P. (2011) La atención integral centrada en la persona. Madrid, Informes Portal Mayores, 106.

Sanz, M. M. F.; de Santiago, F. F. i Cámara, F. J. N. (2011) «Descripción de la calidad de vida en una población anciana institucionalizada». Revista Española de Geriatría y Gerontología, 46(2), p. 111-114.

Vidal-Martí, C. (2016) «Un exemple d'intervenció educativa amb gent gran». Temps d'Educació, 51, p. 299-300. 
Vidal-Martí, C. (2020) La violencia laboral en residencias de mayores. ¿Cómo gestionar la agresividad de la persona usuaria? Barcelona, Horsori.

Vitaliano, P. P.; Russo, J.; Young, H. M.; Becker, J., i Maiuro, R. D. (1991) «The screen for caregiver burden». The Gerontologist, 31(1), p. 76-83.

Yanguas Lezaun, J.J (2006) Análisis de la calidad de vida relacionada con la salud en la vejez desde una perspectiva multidimensional. Madrid, Imserso.

Zamarrón, M. D. i Fernández-Ballesteros, R. (2000) «Satisfacción con la vida en personas mayores que viven en sus domicilios $y$ en residencias: factores determinantes». Revista Española de Geriatría y Gerontología, 35(S2), p. 17-29.

Zarit, S. H.; Reever, K. E.; i Bach-Peterson, J. (1980) «Relatives of the impaired elderly: correlates of feelings of burden». The gerontologist, 20(6), p. 649-655.

Zueras Castillo, P. i Ajenjo Cosp, M. (2016) «Persones grans institucionalitzades a Catalunya: quantes són i com són?». Revista Catalana de Sociologia, 31-2, p. 5-23. 
Resumen: Una de las decisiones más difíciles para una persona dependiente y sus familiares es el ingreso a un centro residencial. Esta decisión conlleva una serie de cambios en la persona y su entorno. Este artículo contribuye a visibilizar la necesidad de cuidar el proceso de adaptación y facilitar el acompañamiento profesional e institucional con el propósito de disminuir el alto impacto emocional que dicho proceso genera. El artículo analiza los diferentes factores que intervienen en el proceso y propone aspectos psicoeducativos para favorecer la acogida y el ingreso de las personas dependientes en el centro residencial.

Palabras clave: personas mayores, discapacidad, ingreso, acompañamiento, apoyo.

\section{Accueil et adaptation des personnes fortement dépendantes dans des cen- tres de soins résidentiels. Aspects psychoéducatifs pour favoriser le proces- sus}

Résumé: L'une des décisions les plus difficiles pour une personne dépendante et pour les membres de sa famille est celle de son placement dans un centre de soins résidentiel. Cette décision entraine une série de changements non seulement pour la personne concernée, mais aussi pour son entourage. Cet article vise à contribuer à la diffusion de cette nécessité de prendre soin du processus d'adaptation et de faciliter l'accompagnement professionnel et institutionnel afin de pouvoir diminuer le grand impact émotionnel généré par ce processus. L'article analyse les différents facteurs qui interviennent dans ce processus et établit des aspects psychoéducatifs afin de favoriser l'accueil et le placement des personnes dépendantes dans le centre de soins résidentiel.

Mots-clés : Personnes âgées, incapacité, placement, accompagnement, soutien

\section{Reception and adaptation of dependent people in care homes. Psychoedu- cational aspects that favour the process}

Abstract: Entering a specialized care home is one of the most difficult decisions for a dependent person and their family members. This decision implies changes in both the person and their environment. The aim of this study is to highlight the need for a careful adaptation process and to provide professional and institutional support in order to mitigate the emotional impact generated by entering a residence. The article analyses the different factors involved in this process and establishes psychoeducational aspects for favouring a positive reception and admission of dependent people in care homes.

Keywords: Elderly, disability, admission, educational support, support. 